\title{
Predictors of Graduate Students' Research Performance in the Philippine State-Run Higher Education Institution
}

\author{
Venessa Sualog Casanova ${ }^{1}$ \\ ${ }^{1}$ Occidental Mindoro State College Main Campus, Labangan Poblacion, San Jose, Occidental Mindoro, \\ Philippines \\ Correspondence: Venessa Sualog Casanova, Occidental Mindoro State College Main Campus, Labangan \\ Poblacion, San Jose, Occidental Mindoro, Philippines. E-mail: venessacasanova@gmail.com
}

Received: March 22, 2021

Accepted: August 21, 2021

Online Published: August 30, 2021

doi:10.5539/jel.v10n5p170

URL: https://doi.org/10.5539/jel.v10n5p170

\begin{abstract}
This descriptive study determined the predictors of research performance of the graduate students in Occidental Mindoro State College, San Jose, Occidental Mindoro, Philippines. This research specifically looked into the graduate students' level of research performance, attitude towards research, challenges encountered, and the strategies employed to cope with the research challenges. A total of 41 completely enumerated students enrolled in Methods of Research and Thesis Writing during the second semester of Academic Year 2018-2019 served as respondents of the study.

The study found that the graduate students' level of research performance is high, specifically in writing the statement of the problem, hypothesis, significance of the study, and definition of terms. They have a positive attitude towards research in terms of usefulness and predispositions. They have negative research anxiety. Challenges encountered include insufficient funds, developing interest, inability to select researchable topics, and limited related literature. Coping strategies employed were frequent consultations with the adviser, seeking help from other competent faculty and students, using technology, and giving material appreciation. Attitude and challenges encountered were found to be predictors of the graduate student's research performance. A positive attitude towards research and the moderate challenges encountered could affect the graduate student's research performance.
\end{abstract}

Keywords: predictors of research performance, level of research performance, attitude towards research, challenges encountered, and coping strategies

\section{Introduction}

Research plays a significant role in everyday daily life. All the inventions and all the things people are enjoying have been possible with the help of research. Furthermore, the knowledge produced by research served as the foundation of sustainable development, which requires that knowledge be used in the service of development, be applied, and be shared to ensure pervasive benefits (University of Skovde, 2016).

In the Philippines, several state universities and colleges have shown distinctive niches in the different fields of research and offer promising and unique platforms in Research, Innovation, and Extension which allow them to engage in discovery and or applied research, disseminate research knowledge, inform government policies, and propel the country's competitiveness in the knowledge-driven global economy (Commission on Higher Education Memo Order No. 52, S. 2016).

In graduate studies, doing research is an essential feature in the students' daily lives (Akyurek \& Afacan, 2018). Graduate education as the apex of the educational system is one of the most effective means of developing capacities related to research that will improve the educational theory and practice in the different aspects of the educational process (Commission on Higher Education Memo Order No. 53, S. 2007).

Attending graduate school is a huge obligation that demands much of the student's time and energy to deal with the academic workload effectively. In addition to that, research also dominates the students' daily lives (Akyurek \& Afacan, 2018). Research methods are considered stressful for many students because they are demanding, overwhelming, and challenging (Papanatsiu, 2014).

The research was regarded as difficult as students hold negative stereotypes towards the subject (Aguiran, Lazo, 
\& Salabat, 2014). Research methods always remained one of the least favorite courses, and most students often perceive them as an impediment in their studies (Papanastasiu, 2014). Students think that it is tough and dry to study research, and they do not understand research concepts and its importance in their professional life. Others dislike research because they do not see themselves as researchers, while others do not feel empowered to understand and use research. Students negatively assumed research because they had to face several obstacles and could not understand the concepts of the research (Shaukat et al., 2014).

On the other hand, some students may take research courses more positively and seriously because they think it would help them in their professional lives. Unfortunately, students who realize the need to spend more time on research activities are even fewer (Siemens et al., 2010). Research must be done precisely and systematically to look for new knowledge, skills, attitudes, and values, or the re-interpretation of existing knowledge. In addition, researchers must possess skills and positive qualities because some unexpected difficulties and problems may be encountered in doing research (Bocar, 2013).

Graduate education is about creating individuals who can ask interesting, demanding, and challenging questions. It is also about skill development that takes the student beyond cultivating a strong analytical mind. Unfortunately, in the review of graduate education, they found out that many are ill-prepared for the full range of roles they must play in academe or beyond. Furthermore, their experience is tarnished by a mismatch between the opportunities available to students as they complete their work and their expectations and training along the way (Polzienne, 2011).

In its effort to raise and maintain the quality of research and address research challenges, Occidental Mindoro State College conducted several intervention programs. Nonetheless, just like the other higher education institutions, they continue to face pressing challenges at various stages of research. It includes improving the research capability, instilling a research culture and vocation, research productivity, and raising quality and impact. (Commission on Higher Education Memo Order No. 52, S. 2016). Thus, this study was conducted.

\section{Objectives of the Study}

This study aims to determine the predictors of research performance of graduate students. Specifically, it aimed to:

1) Determine the respondents' attitude towards research.

2) Find out the challenges encountered by the respondents during the research process.

3) Determine the coping strategies used by the respondents during the research process.

4) Determine the respondents' level of research performance.

5) Determine which among the attitude, challenges encountered, and coping strategies predicts the research performance of the graduate students.

\section{Theoretical Framework}

The study was anchored on the Social Cognitive Theory of Bandura and Walberg's theory on Educational productivity.

The social cognitive theory states that learning occurs in a social context with dynamic and reciprocal interaction of environment and behavior. The theory considers the person's past experiences, which factor into whether behavioral action will occur. These past experiences influence reinforcements, expectations, and expectancies, all of which shape whether a person will engage in specific behavior and why a person engages in that behavior (Lamorte, 2016).

The theory on Educational productivity of Walberg (1981) states that affective, cognitive, and behavioral skills for optimization of learning affect the quality of academic performance such as aptitude (ability, development, and motivation); instruction (amount and quality); and environment (home, classroom, peers, and television).

Graduate students' attitude towards research, the challenges they encountered, the coping strategies they employed while doing research, and their research performance is influence by the dynamic and reciprocal interactions with family members, friends, teachers, and other people in their environment. Thus, their home and school environment could also affect their research performance; their attitude plays a significant role in excelling in their research endeavors.

\section{Conceptual Framework}

The conceptual framework that guided the study is presented in Figure 1. As shown in the research paradigm, the researcher looked into the predictors of the respondents' research performance (DV) level of the graduate 
students. The predictors of the research performance (IV) considered were the respondents' attitude towards research, challenges encountered during the research process, and coping strategies.

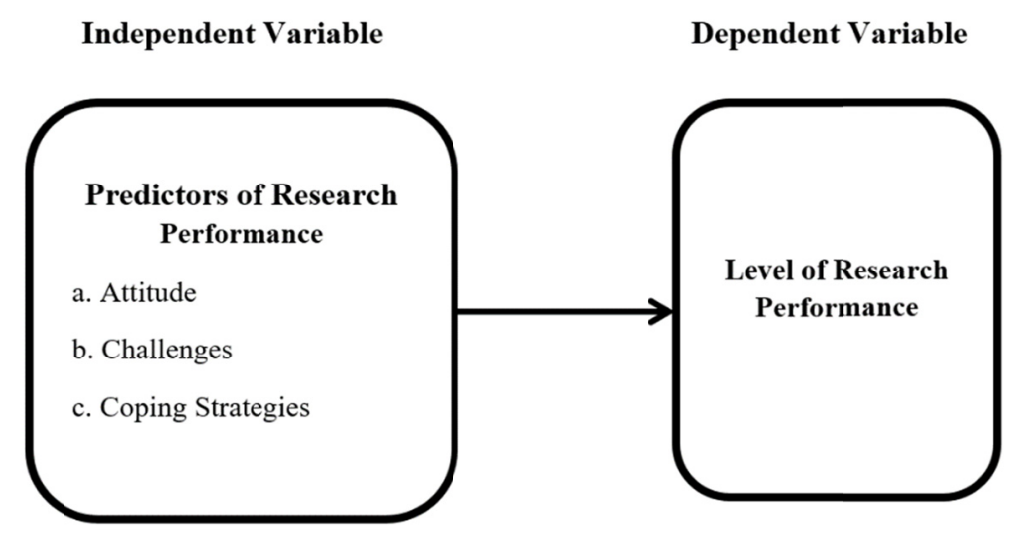

Figure 1. Research paradigm

\section{Research Methodology}

\subsection{Research Design}

This study utilized the descriptive -predictive design to determine which among the attitude, challenges, and coping strategies predicts the level of research performance of the graduate students.

\subsection{Research Locale}

On February 1, 2019 - May 30, 2019, the study was conducted at Occidental Mindoro State College Main Campus, Labangan Poblacion, San Jose, Occidental Mindoro, Philippines.

\subsection{Respondents and Sampling}

A total of 41 graduate students from the three programs: Master in Public Administration, Master of Arts in Education, and Master of Arts in Teaching major in English and Filipino enrolled in Methods of Research, Thesis I, and Thesis II during AY 2018-2019 were the respondents of the study. They were selected through complete enumeration.

\subsection{Research Instrument}

A survey questionnaire was the main instrument used in gathering data for the study. In determining the research performance of the respondents, a validated survey questionnaire of Aguiran, Lazo, and Salabat (2014) was used. Furthermore, the revised research attitude scale of Papanastasiou (2014) was used to determine the graduate student's research attitudes. Whereas, to elicit data for the challenges and coping strategies, the survey questionnaire of Asogwa, Wombo, and Ugwouke (2014) was adopted. All the research instruments used have a reliability coefficient mark which ranges from $.775, .947$, and. 886 , respectively.

\subsection{Data Gathering Procedure}

Before administering the instrument to the respondents, the researcher sought the approval of the school officials. Then, the researcher explained the study's objectives and the ethical consideration of the research to the respondents of the study. Next, the survey questionnaire was administered during the most convenient time of the respondents, and they were given enough time to answer the survey. Finally, the researcher personally administered the research instrument to expedite data collection.

\subsection{Data Analysis}

The data were analyzed using descriptive statistics such as Weighted Mean and Multiple Regression Analysis. The Weighted mean was used to identify the respondent's level of research performance, challenges encountered, and coping strategies. At the same time, the researcher used Multiple Regression Analysis to determine which among the attitude, challenges encountered, and coping strategies predict the graduate student's research performance. 


\section{Results and Discussion}

\subsection{Graduate Students' Attitude Towards Research}

Papanatasiu (2014) defined attitude as the mental, emotional, and behavioral tendencies of a person toward a concept, a situation, an object, and course; attitude towards research, on the other hand, means a thorough study of the cognitive, affective, and the students' conduct towards research. Therefore, it is essential to look into the students' attitude towards research to develop a positive attitude to facilitate learning (Shaukat, Siddiquah, Abiodullah, \& Akbar, 2014).

Table 1 presents that graduate students tended to have a positive attitude towards research, as shown in the 3.73 overall means. The table also shows that the respondents rated the three dimensions of attitude from negative to very positive. The usefulness of the research garnered a very positive attitude (4.70), and positive predispositions (4.17) obtained positive results. It can also be noted that the respondent's anxiety towards research is negative (2.32). The findings implied that the respondents have a favorable attitude towards research. They take research courses more positively and seriously because it would help them in their professional lives (Shaukat, Siddiquah, Abiodullah \& Akbar, 2014).

Table 1. Graduate students' attitude towards research

\begin{tabular}{lll}
\hline Indicator & Mean & Interpretation \\
\hline Usefulness & & \\
Research is helpful for my career. & 4.82 & Very Positive \\
Research is connected to my field of study & 4.65 & Very Positive \\
The skills I have acquired in research will be helpful to me in the future. & 4.82 & Very Positive \\
Research should be indispensable in my professional training & 4.51 & Very Positive \\
Mean & $\mathbf{4 . 7 0}$ & Very Positive \\
Anxiety & & \\
Research courses make me anxious (R). & 2.21 & Negative \\
Research courses scare me (R). & 2.63 & Moderately Positive \\
Research courses are stressful (R). & 2.24 & Negative \\
Research courses make me nervous (R). & 2.46 & Negative \\
Research courses are difficult (R). & 2.04 & Negative \\
Mean & $\mathbf{2 . 3 2}$ & Negative \\
Positive Predisposition & & \\
I enjoy my research course & 4.14 & Positive \\
I love research courses. & 4.14 & Positive \\
I find research courses interesting. & 4.31 & Positive \\
Research courses are pleasant. & 4.07 & Positive \\
Mean & $\mathbf{4 . 1 7}$ & Positive \\
Overall Mean & $\mathbf{3 . 7 3}$ & Positive \\
\hline
\end{tabular}

Note. Scale: 4.51-5.00 Very Positive; 1.51-2.5 Negative; 3.51-4.5 Positive; 1.0-1.5 Very Negative; $2.51-3.5$ Moderately Positive.

\subsection{Challenges Encountered by the Graduate Students During the Research Process}

Challenges could be defined as an undertaking or condition that tests someone's capability. It also refers to the problems encountered in a job or career which test one's ability or resources in challenging but inspiring undertakings (Asogwa, Wombo, \& Ugwouke, 2015). In this study, challenges refer to those difficult situations that graduate students encounter during the research process.

In Table 2, graduate students encountered moderate (2.56) challenges during the research process. The table also shows seven indicators that posed a moderate challenge and eight indicators that show low challenges to the graduate students during the research process. The item developing interest in the topic that my panel of evaluators approved of me got the highest mean (3.46). On the other hand, my adviser and panel members asked me to write and submit to them without any guide or materials got the lowest mean (1.53).

The findings implied that the graduate students encountered low to moderate challenges during the research process because the approved topics are within the range of their interest, and they were given enough support to perform their research activities. The statement supports the findings that the individual's interest in a particular topic is significant. Researching topics that are not of interest could affect the students' performance, and there can be problems in completing the study on time. Further, the supervisors (advisers) should develop research skills and creativity by preparing a conducive research environment, and they are expected to help their students 
overcome research problems (Akyurek \& Afacan, 2018).

Table 2. Challenges encountered by the graduate students during the research process.

\begin{tabular}{lll}
\hline Indicators & Mean & Interpretation \\
\hline Inability to select a researchable topic for my thesis writing. & 3.17 & Moderate \\
Inability to understand and cope with the relationship of concepts in the topic approved for me. & 3.04 & Moderate \\
Inability to source relevant materials to my research topic. & 2.92 & Moderate \\
Developing interest in the topic that my panel of evaluators approved for me. & 3.46 & Moderate \\
The topic approved for me is complex and has scanty literature. & 2.92 & Moderate \\
Inadequate funds to meet the financial demand of thesis writing. & 3.31 & Moderate \\
Respondents demand money to respond to my instrument for data collection. & 1.90 & Low \\
My target respondents denied me access to data collection. & 1.82 & Low \\
There was a demand for cash or materials from the concerned individuals before they give due attention & 1.68 & Low \\
to my work. & & 1.70 \\
My program sponsorship was withdrawn due to a prolonged delay in my thesis writing. & Low \\
My adviser and panel members asked me to write and submit to them without any guide or materials. & 1.53 & Low \\
Late modifications of my topic by my supervisor and panel of evaluators. & 1.85 & Low \\
Nature of job or tight schedule in my place of work tied me down. & 2.87 & Moderate \\
Family responsibilities held me down. & 2.48 & Low \\
Distance between my supervisor and I hindered regular contact. & 2.36 & Low \\
Mean & $\mathbf{2 . 5 6}$ & Moderate \\
\hline
\end{tabular}

Note. Scale: 4.51-5.00 Very High; 1.51-2.5 Low; 3.51-4.5 High; 1.0-1.5 Very Low; 2.51-3.5 Moderate.

\subsection{Coping Strategies Employed by Graduate Students During the Research Process}

Coping is defined as a solid determination to manage and overcome difficulties and serious undertakings that posed a test, danger, harm, loss, or benefit to an individual. It includes self-regulated goal attainment strategies and personal growth (Asogwa, Wombo, \& Ugwouke, 2015).

Table 3 shows that the graduate students sometimes (3.19) employed coping strategies during the research process. Coping strategies such as seeking help from competent faculty and student other than their adviser and consistently visiting their adviser garnered the highest mean (3.92), while hiring a research assistant to facilitate their thesis writing got the lowest mean (1.87). The findings imply that the respondents rely much on their thesis adviser during the entire research process since they considered them the most knowledgeable and the right person who can assist them during their research undertakings. Furthermore, the adviser's field of expertise is vital because they can better guide their students (Arkuryek \& Afacan, 2018).

Table 3. Coping Strategies employed by graduate students during the research process.

\begin{tabular}{lll}
\hline Indicators & Mean & Interpretation \\
\hline I sought help from other competent faculty and students other than my adviser from topic selection to the & 3.29 & Sometimes \\
end of thesis writing. & 3.07 & Sometimes \\
I sourced materials for my Thesis with the help of classmates. & 3.34 & Often \\
I sourced materials from cyber café and libraries with the help of cyber and library attendants. & 3.53 & Often \\
I had to learn computer operations for browsing and data analysis. & 3.92 & Often \\
I consistently visited my advisers' office to check for my Thesis. & 3.70 & Often \\
I sent my Thesis to my adviser and received corrections from him/ her via e-mail, texts, and calls. & Sometimes \\
I arranged with or paid my colleagues to perform some official duties to enable me to have time for my & 2.29 & \\
thesis writing. & 3.68 & Often \\
I gave material appreciation to my adviser and my respondents. & 1.87 & Rarely \\
I hired a research assistant to facilitate my thesis writing. & 3.17 & Sometimes \\
I borrowed money to cope with financial challenges to complete my thesis writing. & $\mathbf{3 . 1 9}$ & Sometimes \\
Mean
\end{tabular}

Note. Scale: 4.51-5.00 Always; 1.51-2.5 Rarely; 3.51-4.5 Often; 1.0-1.5 Never; 2.51-3.5 Sometimes.

\subsection{Level of Research Performance of the Graduate Students}

As shown in Table 4, the level of research performance of the graduate students is high, as reflected in the 3.85 means. Among the indicators of research performance, the graduate students obtained a high level in writing the 
elements of the first chapter of the research, specifically in writing the significance of the study (4.19), formulating hypothesis (4.04), writing the statement of the problem (4.02), and defining terms (4.00). On the other hand, the lowest mean was developing the research tools and instruments (3.63) and analyzing the data. The findings imply that the graduate student possesses enough knowledge and skill to perform research activities, but some areas need improvement. The researchers must possess skills and positive qualities to improve their performance because some unexpected difficulties and problems may be encountered. Research is done precisely and systematically, searching for new knowledge, skills, attitudes, and values, or the re-interpretation of existing knowledge (Bocar, 2013).

Table 4. Level of research performance of the graduate students

\begin{tabular}{lll}
\hline Indicator & Mean & Interpretation \\
\hline Formulating the Research title & 3.73 & High \\
Writing Statement of the Problem & 4.02 & High \\
Making a Conceptual Framework & 3.78 & High \\
Writing the Introduction & 3.87 & High \\
Formulating the Hypothesis & 4.04 & High \\
Writing the Significance of the Study & 4.19 & High \\
Defining Terms & 4.00 & High \\
Designing the Methodology of the study & 3.68 & High \\
Developing the Research Tools and Instruments. & 3.63 & High \\
Analyzing the Data & 3.63 & High \\
Writing and Discussing the Results of the study. & 3.75 & High \\
Formulating the Conclusions and Recommendations & 3.87 & High \\
Mean & $\mathbf{3 . 8 5}$ & High \\
\hline
\end{tabular}

Note. Scale: 4.51-5.00 Very High; 1.51-2.5 Low; 3.51-4.5 High; 1.0-1.5 Very Low; 2.51-3.5 Moderate.

\subsection{Predictors of the Graduate Students' Research Performance}

Table 5 presents that there are two predictors of research performance. First, the attitude towards research predicts research performance as shown in the $.026 \mathrm{p}$-value and the challenges encountered, which obtained a $.034 \mathrm{p}$-value. Second, coping strategies did not predict the graduate students' research performance as reflected in the $.595 \mathrm{p}$-value. Thus, the theory supports the findings of the study on Educational productivity of Walberg (1981), which states that the emotional, cognitive, and behavioral skills needed in the development of learning affect the quality of academic performance such as aptitude, instruction, and environment (Aguiran, Lazo, \& Salabat, 2014).

Table 5. Predictors of the graduate students' research performance

\begin{tabular}{lllll}
\hline Predictors & Dependent variable & Beta Coefficient & p-value & Interpretation \\
\hline Attitude towards research & Research Performance & .339 & .026 & Significant \\
Challenges encountered & & .436 & .034 & Significant \\
Coping strategies employed & & -.107 & .595 & Not Significant \\
\hline
\end{tabular}

\section{Conclusions}

This paper determined the predictors of research performance of the graduate students in Occidental Mindoro State College, San Jose, Occidental Mindoro, Philippines. This research paper specifically looked into the graduate students' level of research performance, attitude towards research, challenges encountered, and the strategies employed to cope with the research challenges. It was found out that graduate students have a positive attitude towards research. The challenges encountered by the respondents during the research process are moderate. They sometimes employ coping strategies, and their level of research performance is high. The predictors of the graduate students' research performance are their attitude towards research and their challenges during the research process. It can be deduced from the findings mentioned earlier that their high level of research performance is influenced by their positive attitude towards research and the moderate challenges they encountered during their research process.

Though the student's overall research performance is high, their research skills are recommended to be strengthened, specifically in developing research instruments and analyzing research data. Research advisers may translate the student's positive attitude toward research productivity by mentoring budding researchers, 
conducting seminars, and advancing policies regarding the use of academic research output. In addition, they may be taught coping skills to handle the challenges encountered during the research process proactively. Reduce environmental stressors by providing a balance of challenge and support to the researchers.

\section{References}

Aguiran, J. M. N., Lazo, R. B., \& Salabat, M. J. C. (2014). Factors affecting students' performance in research. CVCITC Research Journal, 1(2), 37-47. Retrieved January 12, 2019, from https://www.academia.edu/9665870/

Akyurek, E., \& Afacan, O. (2018). Problems encountered during the scientific research process in graduate education: The institute of educational sciences article (PDF Available). Retrieved January 23, 2019, from https://www.researchgate.net/publication/324269589

Asogwa, B. C., Wombo, A. D., \& Ugwouke, C. U. (2015). Challenges and coping strategies adopted by postgraduate students of agricultural education in Thesis writing in Nigerian universities. American Journal of Operations Research, 4, 311-318. https://doi.org/10.4236/ajor.2014.45030

Bocar, A. (2013). Difficulties Encountered by the student-researchers and the effects on their research output. Retrieved February 10, 2019, from https://worldconferences.net/proceedings/gse2013/papers_gse2013/031\%20Anna\%20Bocar.pdf

Commission on Higher Education Memo Order No. 52, S. (2016). Retrieved January 23, 2019, from http://chedresearch.wordpress.com

Commission on Higher Education Memo Order No. 53, S. (2007). Retrieved January 23, 2019, from $\mathrm{http}: / /$ ched.gov.ph/2007-ched-memorandum-orders

Islam, G. M. S. (n.d.). Essay on the importance of research. Retrieved January 10, 2019, from http://www.preservearticles.com/2012071233198/essay-on-the-importance-of-research.html

Lamorte, W. W. (2016). Social Cognitive Theory. Boston University of Public Health. Retrieved January 7, 2019, from http://sphweb.bumc.bu.edu/otlt/MPHModules/SB/BehavioralChangeTheories/BehavioralChangeTheories5. html

Meerah et al. (2011). Measuring Graduate Students Research Skill. Retrieved January 10, 2019, from https://www.sciencedirect.com/science/article/pii/S1877042812038888

Papanastasiou, E. (2014). Revised-Attitudes Toward Research Scale (R-ATR); A First Look at its Psychometric Properties 14. Retrieved January 10, 2019, from http://files.eric.ed.gov/fulltext/EJ1098280.pdf

Polziehn, R. (2011). Skills Expected from Graduate Students in Search of Employment in Academic and NonAcademic Settings. Retrieved January 14, 2019, from https://www.ualberta.ca/graduate-studies/-/media/gradstudies/migratedmedia/profdev/career/careerskillsexp ected.pdf

Shaukat, S., Abiodulla, M., Siddiquah, A., \& Akbar, R. A. (2014). Postgraduate Attitude Towards Research. Retrieved January 23, 2019, from http://pu.edu.pk/images/journal/ier/PDFFILES/7_Sadia,\%20Aishah\%20\&\%20Abiodullah_V36-no1-2014.p df

Siemens, D. R., Punnen, S., Wong, J., \& Kanji, N. (2010). A survey on the attitudes towards research in medical school. B.M.C. Medical Education, 10(4). https://doi.org/10.1186/1472-6920-10-4

University of Skovde. (2016). The importance of research and its impact on education. Retrieved January 28, 2019 , from https://www.studyinternational.com/news/the-importance-of-research-and-its-impact-on-education

\section{Copyrights}

Copyright for this article is retained by the author, with first publication rights granted to the journal.

This is an open-access article distributed under the terms and conditions of the Creative Commons Attribution license (http://creativecommons.org/licenses/by/4.0/). 